\title{
Determinants of Risk-Dependent Agricultural Field Behaviours in Bhutan
}

\author{
Bryan Gensits", Rekha Chhetri, Tshotsho \\ College of Natural Resources, Royal University of Bhutan, Lobesa, Punakha, Bhutan
}

Email address:

bgensits@gmail.com (B. Gensits)

${ }^{*}$ Corresponding author

To cite this article:

Bryan Gensits, Rekha Chhetri, Tshotsho. Determinants of Risk-Dependent Agricultural Field Behaviours in Bhutan. International Journal of Agricultural Economics. Vol. 4, No. 3, 2019, pp. 109-119. doi: 10.11648/j.jjae.20190403.14

Received: April 3, 2019; Accepted: May 9, 2019; Published: June 5, 2019

\begin{abstract}
This article investigates the power of individual risk preference in combination with socio-economic and demographic characteristics to predict ten agricultural field behaviours in a developing country. A sample of 163 farmers from western-central Bhutan was interviewed regarding their farm management practices. Their risk preference was then experimentally elicited using a modified Multiple Price List. The results show farm size as being a primary determinant of income diversification, nitrogenous fertiliser application, and pesticide use. Farm diversification is most dependent on the household head's level of education and the quantity of farm labour available. Finally, both income diversification and farm diversification are shown to have an inverse relationship with loss risk aversion. On the basis of the findings of this article, agricultural policy and programmes can increase their efficacy and efficiency by targeting agrarian Bhutanese households based on their characteristics.
\end{abstract}

Keywords: Farm Diversification, Farmers' Risk Preferences, Income Diversification, Nitrogenous Fertiliser Use, Pesticide Use

\section{Introduction}

Businesses in all sectors of the economy are presented with production risk. With risk emerging from a multitude of sources, agriculture is no exception [1]. Many decisions that farmers face can act to either mitigate or increase their households' exposure to risk, and it has been posited that risk preference is a primary determinant of these risk-dependent field behaviours [2]. Prior literature has refined techniques of experimentally eliciting risk preference with the aim of being able to predict real-world decisions across a variety of domains [e. g. 3, 4, 5]. This article employs a state-of-the-art elicitation technique in combination with socio-economic and demographic characteristics to predict a variety of risk-dependent field behaviours in the developing Himalayan country of Bhutan.

Situated between India and China, Bhutan is a largely agrarian country. In total, $62.7 \%$ of the employed rural population is engaged in subsistence farming [6] and $14.9 \%$ of the country's Gross Domestic Product (GDP) is derived from crops and livestock [7]. Understanding the determinants of field behaviours in a developing country where there is a heavy reliance on agriculture is crucial for forecasting the impact of climatic and economic shifts. Furthermore, it is beneficial for designing effective policy interventions which can act to stabilise food prices and incomes while mitigating any undesirable effects of such changes [8]. This is the first study with the aim of predicting farmers' field behaviours within Bhutan, and it adds to a growing body of literature globally.

The use of experimentally elicited measures of risk preference to predict agricultural field behaviours has had mixed results throughout the recent literature. These findings include risk aversion: 1) delaying the adoption of modern seed varieties [9], 2) having either a positive or an ambiguous effect on fertiliser application $[10,11], 3)$ increasing pesticide use [9, $12,13], 4)$ either increasing or having no significant effect on crop diversification [13, 14], and 5) decreasing farm production risk [15]. Based on the results of such prior literature, further investigation and result verification in new regions are essential. 
This paper is designed to contribute to the empirical literature by increasing the understanding of the drivers of risk-dependent agricultural field behaviours in developing countries. To this end, this paper's objectives are: 1) to measure individual risk preferences for both gains and losses, 2) to make quantitative measurements of a set of ten field behaviours which prior literature has shown to be potentially risk-dependent, and 3) to determine which factors are significant in determining the set of risk-dependent field behaviours through the use of a multivariate regression analysis. While the bulk of prior literature focuses on the effect of risk preference on one field behaviour [Hellerstein, Higgins [14] being a notable exception], this article seeks to broadly investigate its effect across a variety of domains in a single location. In the context of changing environmental and economic conditions, quantifying the determinants of farm behaviours has important implications for policy makers, extension agents, and non-profit organisations operating in the region. These include improved forecasting ability and increased intervention efficiency through targeted initiatives.

This article is organised as follows. The Methodology section details the study site, sample, interview procedure, and risk preference elicitation and reporting. Additionally, the ten field behaviour metrics which were utilised are comprehensively covered under the Methodology. The Results section is broken into two subsections. The first, Descriptive analysis of the variables, explores both the independent and dependent variables used for the multivariate regression analysis. The second, Tobit model results and discussion, gives the regression estimations and briefly discusses the relevant findings. This is followed by a Discussion section which explores the most important results further and considers the potential limitations of this study while presenting prospective future research in the field. Finally, a Conclusions section summarises the findings of this article and presents policy implications for Bhutan.

\section{Methodology}

The methodology that this article employed is thoroughly described in the following sections. An emphasis is placed on how risk preference was elicited and the definitions of the risk-dependent agricultural field behaviours.

\subsection{Study Site}

Bhutan is a small mountainous country in southeast Asia with a majority rural, agrarian population [6]. Recognising the central role of both sustainable and profitable farming to improving rural livelihoods, the Royal Government of Bhutan (RGOB) has an ambitious vision for the future of Bhutan's agriculture. While earlier in the century the RGOB had aimed at transitioning the country's agriculture to be completely organic by 2020, achieving this goal now appears increasingly unlikely $[16,17]$. The lack of a substantial body of research in the country is largely to blame for missing this target, and this article seeks to begin to fill that gap. Further, as a result of climate change, Bhutan is 'projected to experience unprecedented heat during more than half of the summer months' [18] by the end of this century; this will place significant stress on farming. The climate-induced risks to Bhutan's agricultural sector and consequently to its food security are not trivial in a country where $8.1 \%$ of rural households already experience food insufficiency and nearly half of the nation's food demand is met by imports $[6,19]$. These factors, et al., highlight the critical role of continued research to further isolate what most influences farmers' decision-making and will assist in the creation of policy interventions that can act to stabilise yields and rural incomes. Ideally, this will be achieved while shifting towards RGOB's vision for sustainability and self-sufficiency in the country's agricultural sector.

\subsection{Sample}

Considering prior risk preference research in combination with the budgetary and time resources available, a sample of 163 households was identified. The sample was drawn from two of Bhutan's twenty dzongkhags (districts). The dzongkhags selected, Punakha and Wangdue Phodrang (collectively known as the Punakha-Wangdue valley), were chosen because of both their relative accessibility and the prevalence of rice production. Combined, these two dzongkhags are responsible for $26.9 \%$ of Bhutan's rice production by weight and are home to $24.2 \%$ of the country's rice cultivation area [7]. The ubiquity of rice cultivation throughout the region enabled the use of three of the field behaviour metrics which would have been considerably more challenging to calculate if a single, dominant crop was not present in the study area.

Punakha and Wangdue Phodrang are composed of eleven and fifteen gewogs (blocks) respectively. Seven gewogs were randomly selected at random from each dzongkhag for sampling. Finally, a probability proportional to size sample was determined for each gewog using agricultural census data provided by the dzongkhag administrations. In total, 163 households dispersed throughout 41 villages were interviewed.

\subsection{Interview Procedure}

The interviews were conducted throughout April and May of 2018. Each interview was carried out in-person and individually at the respondent's home. This enabled much of the information provided by the respondent to be observationally authenticated. The interviews began by verifying that the respondent is either the primary agricultural decision maker for the household or that they are an equal member in a joint decision-making process (hereafter referred to as the Head of Household or $\mathrm{HoH}$ ). This step ensured that the experimentally elicited risk preference would correspond to the household's field behaviours.

The interview process employed a closed-ended questionnaire which was orally administered. The questionnaire detailed demographic and socio-economic information, agricultural field behaviours, and experimentally 
elicited risk preferences. The information gathered included all cereal, fruit, and vegetable production as well as seed choice on a per crop basis. Fertiliser and pesticide application rates for rice were also obtained. Farmers in the Punakha-Wangdue valley generally use local names for nationally-available fertilisers and pesticides. Therefore, a pictorial pamphlet was used during the interview to allow the respondent to visually identify each product that they applied. Participants were also asked to show their chemical storage room to the interview team as an additional confirmation. Additionally, the household agricultural income was exhaustively detailed on a per product basis and all non-agricultural income sources were also recorded. Various other relevant demographic, socio-economic, and agricultural data were obtained which aided in the development of both the field behaviour metrics and the independent variable list for the regression analysis.

\subsection{Risk Preference Elicitation and Reporting}

This study orally elicited individual risk preferences using an incentivised Lottery Choice Task (LCT). The LCT was partially derived from Tanaka, Camerer [20] and popularised in the agricultural sector by articles such as Liu [21] and Liu and Huang [9]. The traditional procedure presents participants with decisions between dichotomous lottery pairs in the format of a LCT. After pretesting a LCT format which generally resembled the models employed by Tanaka, Camerer [20] and Holt and Laury [22], changes were deemed necessary as comprehension was low during oral administration. The LCT this study developed was constructed of decisions which are stacked in rows with two columns labelled 'Option A' and 'Option B'. For each row, participants are asked to choose which gamble they prefer from the two options. 'Option A' contained a fixed, certain pay-off or loss of Ngultrum $^{1}$ (Nu.) 100 while 'Option B' contained a binary prospect. 'Option B' was presented to participants as a coin flip gamble which was found to be a familiar reference for the sample population. The 'Heads' prospect remained static at $\mathrm{Nu}$. 0 throughout each sequence while the 'Tails' outcome varied. Containing two fixed and one moving value, this design allowed for maximal understanding while preserving the ability of a robust risk preference elicitation to occur. The gain and loss LCT developed and used by this study is described in Table 1 .

Table 1. Lottery sequences.

\begin{tabular}{lllllll}
\hline & \multicolumn{3}{l}{ Gain sequence } & \multicolumn{3}{l}{ Loss sequence } \\
\cline { 2 - 7 } Set no & Option A & \multicolumn{2}{l}{ Option B } & \multicolumn{2}{l}{ Option A } & \multicolumn{2}{l}{ Option B } \\
\cline { 2 - 7 } & Certain & Heads & Tails & Certain & Heads & Tails \\
\hline 1 & 100 & 0 & 120 & -100 & 0 & -120 \\
2 & 100 & 0 & 180 & -100 & 0 & -180 \\
3 & 100 & 0 & 230 & -100 & 0 & -230 \\
4 & 100 & 0 & 500 & -100 & 0 & -500 \\
5 & 100 & 0 & 1000 & -100 & 0 & -1000 \\
\hline
\end{tabular}

All values presented are in the local Ngultrum currency.

\footnotetext{
${ }^{1}$ Ngultrum is the currency of Bhutan and is fixed to the Indian rupee. At the time of writing $\$ 1.00=$ Nu. 71.16 .
}

The LCT was divided into two sequences: a gain sequence and a loss sequence. The inclusion of a negative, but otherwise identical, independent loss sequence is advantageous because of the asymmetries in risk preference which are present between potential gains and losses [23]. The gain sequence was incentivised to ensure participants were sufficiently motivated to reveal their true preferences. Prior to beginning the LCT, participants were instructed that a real payoff will be given and that it will be determined by their decision in a randomly selected set at the interview's conclusion. Unlike the gain sequence, the loss sequence is non-incentivised to ensure that participants are not at risk of losing money during the experiment.

There are various metrics which can be used to report individual risk preference for analysis. Prior literature frequently employs the Coefficient of Relative Risk Aversion (CRRA) to describe risk preference [e. g. 3, 4, 9]. For the analysis, a similar measure to Hellerstein, Higgins [14]'s use of the 'number of risky decisions' a participant made in a sequence was used en lieu of CRRA. The use of the number of risky decisions metric, as opposed to CRRA, has the potential to be more reliable as it does not make assumptions about the functional form or utility process associated with risk. However, the number of risky decisions metric may not linearly correspond to the risk of the LCT.

To quantify risk preference, this study measured the number of times a respondent chose the safer option in the gain and loss sequences. The variables are referred to as the Gain safe decisions (decs.) and the Loss safe decisions (decs.) respectively. These intuitive metrics increases with risk aversion. For example, a respondent who maximises expected utility in the gain sequence would switch from Option A to Option B in-between set two and three. She would thus be said to have two Gain safe decisions.

Some prior studies which relied on LCTs have had to devise methods to contend with participants who violate Von-Neumann and Morgenstern [24]'s axiom of transitivity by switching between columns in the same sequence more than once. An analysis of risk elicitation studies demonstrated that the available methods of handling observations where inconsistent choices were present introduced systematic bias to the sample's risk preference mean and variance [25]. The team concluded that if a large proportion of a sample violates transitivity, the study's risk elicitation procedure must be 'critically reconsidered' as all available methods risk biasing the data [25].

Only one participant in this study made multiple switches and their results were dropped from the analysis. A single dropped observation in a sample of 163 households poses no risk of introducing bias into the model. In addition, the absence of widespread transitivity violations in this study's results is indicative of the effectiveness of the method used to elicit individual risk preference without introducing unnecessary complexities. More involved procedures may detract from participants' ability or willingness to accurately reveal their risk preferences. 


\subsection{Field Behaviours}

A total of ten risk-dependent agricultural field behaviours were selected. These can be divided into three subsets: Farm diversification metrics, Financial metrics, and Farm management metrics. The dependent variables are discussed thoroughly in the subsequent sections and are summarised in Table 2 .

Table 2. Dependent variables.

\begin{tabular}{|c|c|c|}
\hline Variable & Code & Conceptual range \\
\hline \multicolumn{3}{|l|}{ Farm diversification metrics } \\
\hline Proportion of products raised & PPR & $0-1$ \\
\hline Berry index-land & BI-L & $0-1$ \\
\hline Shannon-Wiener entropy measure-land & SWEM-L & $0-\infty$ \\
\hline \multicolumn{3}{|l|}{ Financial metrics } \\
\hline \multicolumn{3}{|l|}{ Farm diversification metrics } \\
\hline \multicolumn{3}{|l|}{ Financial metrics } \\
\hline Berry index-income & BI-I & $0-1$ \\
\hline Shannon-Wiener entropy measure-income & SWEM-I & $0-\infty$ \\
\hline Debt-income ratio $^{\mathrm{a}}$ & DIR & $0-\infty$ \\
\hline \multicolumn{3}{|l|}{ Farm management metrics } \\
\hline Modern rice adoption proportion ${ }^{\mathrm{b}}$ & MRAP & $0-1$ \\
\hline Standardised nitrogen application index ${ }^{\mathrm{b}}$ & SNAI & $0-1$ \\
\hline Standardised pesticide application index ${ }^{b}$ & SPAI & $0-1$ \\
\hline Trial & TRL & 0,1 \\
\hline
\end{tabular}

${ }^{\mathrm{a} O n l y}$ households that reported income during 2017. ${ }^{\mathrm{b}}$ Only households that reported growing rice during 2017.

\subsubsection{Farm Diversification Metrics}

The first subset of variables is farm diversification metrics. The diversification of agricultural outputs is one of the most direct methods of reducing risk exposure in a farming operation. [26, 27]. Agricultural diversification is broadly associated with farmers growing an increasing number of crop species and rearing new breeds of livestock [28]. Producing a wide variety of crops and livestock, especially when the success of one is not correlated with that of another, diffuses risk across a farming operation [29]. This reduces the likelihood of a complete crop failure occurring as this type of event would be more likely to affect a mono-crop operation. Such farms introduce the risk of a single disease destroying an entire harvest, especially when only one genetic variety is present $[30,31]$. In addition, farm diversification has benefits which include poverty alleviation [32, 33], increased profitability [34], improved food security [35], and decreased yield variability [36].

Through detailing every cereal, vegetable, fruit, and livestock variety that was present at each household, highly representative metrics were able to be produced. Three such measures of farm diversification were generated. Each uniquely measures richness or a combination of both richness and relative abundance. All metrics are calculated so that the value of the metric increases with the level of diversification. Following with Asravor [13]'s findings, it is hypothesised that as farm diversification decreases the risk exposure of the operation increases, and the farmer's risk aversion correspondingly increases.

When calculating the farm diversification metrics, all outputs are assumed to have equal production risk. Attempting to precisely quantify production risk for each possible crop and livestock combination would require an analysis of the variance of net yields for all farm output scenarios. This is far beyond the scope of this study, but such an analysis of Bhutanese agricultural production would be a valuable addition to the literature.

The first farm diversification metric is the Proportion of products raised (PPR). This variable is similar to McNamara and Weiss [37]'s 'Modified concentration ratio' and Hellerstein, Higgins [14]'s 'Number of products not raised'. PPR measures richness but does not reflect relative abundance. The PPR of the $i^{\text {th }}$ household is defined as $Q_{i} / Q_{\max }$ where $Q_{\max }$ is the maximum number of crop and livestock varieties present at any household surveyed and $Q_{i}$ is the number of varieties present at the $i^{t h}$ household. PPR is the only farm diversification metric to include livestock but it is also the crudest metric utilised since it does not account for the quantity of land devoted to each activity.

The second farm diversification metric is a Berry index (BI) [38]. The $\mathrm{BI}$ is commonly used to measure land use diversification [e. g. 37, 39]. It is also known as the Herfindahl-Hirschman index (economics) and the Simpson index (ecology). The BI is a measure of both richness and relative abundance. It is defined for a household as $1-\sum p_{i}^{2}$ where $p_{i}$ is the proportion of cultivated area devoted to growing the $i^{\text {th }}$ crop. The BI is limited by its lack of ability to account for owned livestock but it is well suited to measuring diversification in regards to a household's land use.

The final measure of farm diversification is a Shannon-Wiener entropy measure (SWEM) [40, 41]. The SWEM for a household is defined as $1-\sum p_{i}^{2}$ where $p_{i}$ is the proportion of cultivated area devoted to growing the $i^{\text {th }}$ crop. Similar to the BI, the SWEM is a quantification of richness and relative abundance, but it is more sensitive to small changes in farm composition since it relies on a logarithmic measure [42]. Since both BI and SWEM are also used to measure income diversification, they are given a '-L' suffix when referring to land diversification.

\subsubsection{Financial Metrics}

The second subset of variables to be predicted are three financial metrics. The first two financial metrics are measures of income diversification. Through the same mechanisms that cause stock-portfolio diversification to negatively affect realised risk $[43,44]$, households may be able to reduce their income variance and risk exposure through the diversification of income streams [45]. Employing two of the same methods which were used to determine land diversification, a BI and a SWEM are used to measure income diversification for each household. These metrics are calculated using the aforementioned equations with the distinction that $p_{i}$ denotes the proportion of the household's total annual income that was derived from the $i^{\text {th }}$ source during 2017. Both indices are 
given a '-I' suffix to denote referring to income diversification. Similar to the farm diversification metrics, the model assumes that there is equal risk associated with all income streams. Despite it being likely that income derived from on-farm activities carries greater risk than that from off-farm sources, precisely accounting for differences in risk through an income variance analysis for all possible income stream combinations is beyond the scope of this study.

These two financial metrics were chosen in part because there is no evidence to suggest a significant correlation between farm diversification and income diversification in a region with a prevalence of subsistence agriculture. For example, a farmer might grow a wide array of crops to diffuse risk, but the quantity of crops harvested does not exceed the household's food demand as a result of not specialising for commercialisation. In this instance, her level of farm diversification would be relatively high and her level of income diversification would be relatively low. Similar to farm diversification, income diversification is only capable of reducing risk if returns are not correlated. It is important for these two types of diversification to be independently measured and the determinants of both to be tested to establish which method (s) risk-averse households use to reduce risk exposure.

The final financial metric is a Debt-income ratio (DIR). A household's DIR is defined as $D b t /$ Inc where $D b t$ is the total amount of outstanding debt at the end of 2017 and Inc is the total income of the household in the same year. It is hypothesised that there is an inverse relationship between DIR and risk aversion. The link between risk aversion and lower debt levels has been established in other fields $[46,47]$ and it is plausible that this would extend to the agricultural context although it has not been documented.

\subsubsection{Farm Management Metrics}

The final subset of variables to be predicted are farm management metrics. Hellerstein, Higgins [14] described the potential for individual risk preference to be able to predict agricultural practices in the context of developing countries since risk mitigating measures and inputs are minimal when compared to what is available in most developed regions. The limited options for farmers make it possible to construct robust metrics that thoroughly describe the risk-reducing behaviour. Four such metrics were developed and are defined below.

Rice is the primary crop grown in the Punakha-Wangdue valley. Extension agents and Renewable Natural Resources Research Centres have made a concerted effort to promote the adoption of modern rice varieties since the first such strain was introduced to Bhutan in 1988 [48]. There is a paucity of substantial, systematic reporting on rates of adoption, but the best available data suggest that $59.9 \%$ of households country-wide have begun cultivating modern varieties on at least some of their land [48]. Since farmers are unsure of modern variety yields, it is posited that more risk-averse farmers will allocate less area to modern crop strains than risk seeking farmers [49, 50]. Liu [21] demonstrated this inverse relationship between risk aversion and the adoption of modern Bt-cotton among farmers in China.

The dependent variable Modern rice adoption proportion (MRAP) was generated using the rice variety information collected. MRAP is defined as $A_{m d n r} / A_{\text {totr }}$ where $A_{m d n r}$ is the area cultivated with modern rice varieties and $A_{\text {totr }}$ is the total area which the household devoted to rice cultivation in 2017. As MRAP increases, modern rice varieties are present on a larger proportion of the household's land. This adoption is hypothesised to be influenced by a decrease in risk aversion.

A primary constraint to rice production in Bhutan is low soil fertility [48]. Prior research has indicated that a negative relationship exists between risk aversion and fertiliser application although this effect diminishes with increasing wealth [11, 51]. Conversely, Le Cotty, Maître d'Hôtel [10] found no link between risk preference and fertiliser application. The lack of a consensus pertaining to this relationship makes it a relevant field of inquiry.

The only nitrogenous fertilisers which were applied in the study area during 2017 were Suphala-15 (15-15-15) and Urea (46-0-0). Dependent variable Standardised nitrogen application index (SNAI) is derived from the application of these products. The SNAI for the $i^{t h}$ household is defined as $\frac{\delta_{i}-\delta_{\min }}{\delta_{\max }-\delta_{\min }}$ where $\delta_{i}$ is the nitrogen application intensity of the $i^{\text {th }}$ household and $\delta_{\min }$ and $\delta_{\max }$ are the minimum and maximum nitrogen application rates of all households surveyed respectively. The intensity of application for the $i^{\text {th }}$ household is defined as $\delta_{i}=Q_{N} / A$ where $Q_{N}$ is the weight of nitrogen applied during the 2017 season over the rice cultivation area $A$. For consistency and ease of comparison, SNAI is limited to nitrogen application over plots where rice cultivation occurred in 2017. The SNAI is calculated as a household score that is between one and zero. A higher SNAI denotes more fertiliser application which is hypothesised to be the result of decreasing risk aversion.

In addition to low soil fertility, insects and weeds are also major constraints to Bhutan's rice production [48, 52]. The application of pesticides may act to mitigate the production risk associated with the threat of such pests. Prior literature has established a positive relationship between risk aversion and pesticide application although the size of the effect may be marginal $[9,13]$.

The pesticides which were found to be present in the study area were herbicide Butachlor $\left(\mathrm{C}_{17} \mathrm{H}_{26} \mathrm{ClNO}_{2}\right)$, herbicide Ethoxysulfuron $\left(\mathrm{C}_{15} \mathrm{H}_{18} \mathrm{~N}_{4} \mathrm{O}_{7} \mathrm{~S}\right)$, and insecticide Cypermethrin $\left(\mathrm{C}_{22} \mathrm{H}_{19} \mathrm{Cl}_{2} \mathrm{NO}_{3}\right)$. The application of these products serves as the basis for the dependent variable Standardised pesticide application index (SPAI). A household's SPAI is defined as the arithmetic mean of the standardised application indices for all three pesticides $\bar{\zeta}$. 
Standardised application index $\zeta$ is calculated individually for each pesticide found in the study area. $\zeta$ is defined as $\frac{\delta_{i}-\delta_{\min }}{\delta_{\max }-\delta_{\min }}$ where $\delta_{i}$ is the pesticide application intensity of the $i^{\text {th }}$ household and $\delta_{\min }$ and $\delta_{\max }$ are the minimum and maximum pesticide application rates of all households surveyed respectively. The pesticide application intensity $\delta$ is defined as the quantity of pesticide over the application area. The calculation of SPAI yields a household score between zero and one where a larger value is indicative of a greater pesticide application intensity which is hypothesised to be the result of risk aversion.

The final dependent variable is based on the premise that farmers' participation in on-farm trials is a function of the perceived riskiness of the crop to be tested [53]. It is hypothesised that individual risk preference would be predictive of a household's participation in on-farm trials because new crops have uncertainty and a greater perceived risk than known varieties do. During the data collection process, respondents were asked to detail their household's participation in on-farm seed trials between 2015 and 2017. The final dependent variable is dummy Trial (TRL). A score of one denotes that the household participated in at least one on-farm trial during the three-year period and zero indicates no trial participation in that time.

\subsection{Empirical Model}

The primary analysis employed a multivariate regression model to establish the determinants of a priori field behaviours. It was hypothesised that these decisions are a function of an array of variables:

$$
\text { Field Behaviour }=f\left(\begin{array}{l}
\text { Age, Sex, Education, Income, Farm size, } \\
\text { Power-tiller, Labour, Labour deficit, } \\
\text { Extension, Gain safe decs., Loss safe decs. }
\end{array}\right)
$$

The selected independent variables are defined in Table 3. In addition to the independent variables listed, a village dummy was included to control for local factors such as elevation, soil type, temperature, and precipitation.

Table 3. Independent variables defined.

\begin{tabular}{ll}
\hline Variable & Description (Units) \\
\hline Age & Age of the head of household (Years) \\
Sex & Gender of the head of household (1: Female) \\
Education & Formal education of the head of household (Years) \\
Income & Total household income for 2017. (1, 000 Ngultrum) \\
Farm size & Size of farm (Acres) \\
Power-tiller & Household uses a power-tiller (1: Use a power-tiller) \\
Labour & Number of full time, adult labourers present (Number of persons) \\
Labour deficit & Number of full time, adult labourers needed for optimal performance minus number present (Number of persons) \\
Extension & Average number of agriculture and livestock extension agent visits per year \\
Gain safe decs. & Number of safe decisions in the gain sequence \\
Loss safe decs. & Number of safe decisions in the loss sequence \\
\hline
\end{tabular}

A multivariate Tobit regression model [54] was used to predict a priori field behaviours with the exception of dummy variable TRL which necessitated the use of a Probit model. The Tobit model was adopted because of the presence of observations clustered at the upper or lower limits for some of the dependent variables. This clustering is described in Table 4. An Ordinary Least Squares (OLS) regression model using the complete dependent variable sample would produce a biased coefficient [54]. In instances where no observations are present at the limiting value (s), the Tobit model acts as an OLS model making it appropriate for use across all iterations even when clustering is nominal or not present.

The multivariate Tobit model is defined as:

$$
V_{i}^{*}=\beta_{1} X_{1}+\beta_{2} X_{2}+\ldots+\beta_{n} X_{n}+\eta_{v}+\varepsilon_{i}
$$

$$
y=\left\{\begin{array}{l}
l \text { if } V_{i}^{*} \leq l \\
V_{i}^{*} \text { if } l<V_{i}^{*}<u \\
u \text { if } V_{i}^{*} \geq u
\end{array}\right.
$$

where $V_{i} *$ is the latent variable that predicts field behaviours, $\beta_{n}$ is the beta coefficient for the $n^{\text {th }}$ independent variable, $X_{n}$ is the $n^{\text {th }}$ independent variable, $\eta_{v}$ is a village dummy, $\mathcal{E}$ is a normally distributed error term, $V_{i}$ is the censored dependent variable, and $l$ and $u$ are lower and upper limits respectively. The regression models defined in Equations (2) and (3) were estimated for all the field behaviours using the censoring limits described in Table 4.

\section{Results}

The results of this article are described in the following 
sections. These include the descriptive analysis of the independent and dependent variables and the Tobit regression model estimations.

\subsection{Descriptive Analysis of the Variables}

The dependent variables used in the regression analysis are described in Table 4. In addition to summary statistics, the applicable upper and lower Tobit limits with any clustering that occurs there is shown. The most extreme clustering occurs at the lower limit for MRAP since 115 of the 147 rice producing farms did not grow any modern varieties in 2017. DIR also has substantial lower limit clustering which reveals that $59 \%$ of the population did not have any outstanding debt. Clustering for income diversification metrics BI-I and SWEM-I shows that $15 \%$ of households only had one income source during 2017. Finally, nitrogenous fertilisers were not applied by $46 \%$ of the population and only $6 \%$ did not use pesticides.

Table 4. Dependent variables described and Tobit limits.

\begin{tabular}{llllll}
\hline Tobit limits & & & & & \\
\hline Variable code & Number of observations & Mean & Standard deviation & Lower limit (Observations) & Upper limit (Observations) \\
\hline PPR & 163 & 0.47 & 0.18 & $0(0)$ & $1(1)$ \\
BI-L & 163 & 0.65 & 0.18 & $0(1)$ & $1(0)$ \\
SWEM-L & 163 & 1.50 & 0.46 & $0(1)$ & No limit \\
BI-I & 157 & 0.43 & 0.27 & $0(23)$ & $1(0)$ \\
SWEM-I & 157 & 0.82 & 0.55 & $0(23)$ & No limit \\
DIR & 153 & 0.78 & 1.80 & $0(90)$ & $1(10)$ \\
MRAP & 147 & 0.13 & 0.29 & $0(115)$ & $1(1)$ \\
SNAI & 142 & 0.16 & 0.23 & $0(66)$ & $1(0)$ \\
SPAI & 139 & 0.15 & 0.13 & $0(9)$ & N/A \\
TRL & 163 & 0.39 & 0.49 & N/A & \\
\hline
\end{tabular}

${ }^{\mathrm{a}}$ Dummy variable.

The independent variables are described in Table 5. and reveal that the average $\mathrm{HoH}$ is a 49 -year-old woman. The level of education is very low as most farmers have no formal education. However, a minority are educated and some even hold a 3 -year college degree. The mean farm size is 2.30 acres and the average annual household income during 2017 was $\mathrm{Nu}$. 159,260 which is equivalent to $\$ 2,238$. Additionally, the average farm has 2.48 full-time adult workers present but an additional 1.29 people are required for optimal performance, making labour a limiting input.

Table 5. Independent variables described.

\begin{tabular}{lllll}
\hline Variable & Mean & Standard deviation & Minimum & Maximum \\
\hline Age & 49.42 & 14.22 & 20 & 0 \\
Sex & 0.60 & 0.49 & 0 & 1 \\
Education & 1.40 & 3.10 & 0 & 15 \\
Income & 159.26 & 198.83 & 0.05 & 1608.21 \\
Farm size & 2.30 & 1.72 & 0 & 10.87 \\
Power-tiller & 0.82 & 0.39 & 1 & 6 \\
Labour & 2.48 & 1.03 & 0 & 1 \\
Labour deficit & 1.29 & 1.05 & 1 & 5 \\
Extension & 8.70 & 5.71 & 0 & 35 \\
Gain safe decs. & 1.63 & 2.21 & 0 & 5 \\
Loss safe decs. & 3.65 & 1.62 & 5 \\
\hline
\end{tabular}

${ }^{\mathrm{a} D u m m y ~ v a r i a b l e . ~}$

\subsection{Tobit Model Results and Discussion}

The results of the Tobit model are described in Table 6 . In addition to the Tobit beta coefficient, McFadden's pseudo- $R^{2}$ is reported for each iteration. McFadden's pseudo- $R^{2}$ is defined as $1-\left(\frac{\ell_{M}}{\ell_{0}}\right)$ where $\ell_{M}$ is the log-likelihood of the fitted model and $\ell_{0}$ is the log-likelihood of the intercept model which contains no covariates.

Table 6. Tobit model results.

\begin{tabular}{|c|c|c|c|c|c|c|c|c|c|c|}
\hline & \multicolumn{3}{|c|}{ Farm Diversification Metrics } & \multicolumn{3}{|c|}{ Financial Metrics } & \multicolumn{4}{|c|}{ Farm Management Metrics } \\
\hline & PPR & BI-L & SWM-L & BI-I & SWEM-I & DIR & MRAP & SNAI & SPAI & TRL $^{\mathrm{a}}$ \\
\hline Age & $\sim 0$ & $\sim 0$ & $\sim 0$ & $-0.01 * * *$ & $-0.01 * * *$ & -0.03 & $0.02 *$ & $\sim 0$ & $\sim 0$ & $\sim 0$ \\
\hline Sex & $\sim 0$ & 0.04 & 0.12 & $-0.11 * *$ & $-0.22 * *$ & 0.13 & -0.25 & 0.08 & $\sim 0$ & 0.15 \\
\hline Education & $0.02 * * *$ & 0.01 & $0.03 * *$ & $\sim 0$ & $\sim 0$ & $\sim 0$ & $0.11 * * *$ & $\sim 0$ & 0.01 & 0.07 \\
\hline Income & $\sim 0$ & $\sim 0$ & $\sim 0$ & $\sim 0$ & $\sim 0$ & $\sim 0$ & $\sim 0$ & $\sim 0$ & $\sim 0$ & $\sim 0$ \\
\hline Farm size & $0.03 * * *$ & $\sim 0$ & -0.01 & $0.06 * * *$ & $0.12 * * *$ & 0.21 & 0.14 & $-0.04 *$ & $-0.03 * * *$ & 0.09 \\
\hline Power-tiller & 0.05 & $\sim 0$ & -0.02 & 0.01 & -0.02 & $1.79 *$ & $-1.15^{* *}$ & 0.05 & 0.03 & $0.90 *$ \\
\hline
\end{tabular}




\begin{tabular}{|c|c|c|c|c|c|c|c|c|c|c|}
\hline & \multicolumn{3}{|c|}{ Farm Diversification Metrics } & \multicolumn{3}{|c|}{ Financial Metrics } & \multicolumn{4}{|c|}{ Farm Management Metrics } \\
\hline & PPR & BI-L & SWM-L & BI-I & SWEM-I & DIR & MRAP & SNAI & SPAI & TRL $^{\mathrm{a}}$ \\
\hline Labour & $0.02 *$ & $0.04 * *$ & $0.09 * *$ & 0.01 & 0.03 & -0.38 & $0.33 * *$ & 0.02 & 0.01 & $0.33 *$ \\
\hline Labour deficit & -0.01 & 0.01 & 0.03 & 0.01 & 0.03 & 0.33 & 0.13 & -0.02 & 0.01 & 0.23 \\
\hline Extension & $\sim 0$ & $0.01 *$ & $0.01 *$ & $0.01 *$ & 0.01 & 0.09 & $0.07 *$ & $-0.02 *$ & $\sim 0$ & 0.01 \\
\hline Gain safe decs. & $\sim 0$ & $0.01 *$ & 0.02 & $0.04 * * *$ & $0.08 * * *$ & -0.23 & -0.10 & $\sim 0$ & 0.01 & -0.02 \\
\hline Loss safe decs. & -0.01 & $-0.03 * * *$ & $-0.07 * * *$ & $-0.04 * *$ & $-0.08 * *$ & $0.38 *$ & 0.08 & $\sim 0$ & $-0.01 * *$ & -0.06 \\
\hline Constant & $0.37 * * *$ & $0.56 * * *$ & $1.18 * * *$ & $0.72 * * *$ & $-1.26 * * *$ & -0.31 & $-1.93 *$ & 0.18 & 0.11 & -2.11 \\
\hline McFadden's $R^{2}$ & -1.43 & -1.02 & 0.44 & 0.98 & 0.40 & 0.27 & 0.65 & 0.76 & -0.55 & 0.24 \\
\hline
\end{tabular}

${ }^{\text {a }}$ Probit model. $P$-values: ${ }^{*} \mathrm{p} \leq 0.10,{ }^{* *} \mathrm{p} \leq 0.05,{ }^{* * *} \mathrm{p} \leq 0.01$.

The Tobit regression model shows that nearly all the tested independent variables have predictive power with respect to at least one dependent variable. A notable exception to this is income which has a Tobit coefficient of approximately zero and does not cross a critical p-value $p \leq 0.10$ across all iterations. Independent variable labour deficit also holds no predictive power for any of the tested field behaviours.

Measuring species richness in farm diversification, PPR is predicted by education, farm size, and labour. The indices BI-L and SWEM-L, which measure both richness and relative abundance, are predicted by education (SWEM-L only), labour, extension, gain safe decisions (BI-L only), and loss safe decisions. It is thus evident that increases in education, labour, and visits from extension agents have a small, positive effect on farm diversification. Meanwhile, increasing the farm size will increase species richness, but has no significant effect on relative abundance. It is also notable that the number of risky decisions for losses has an inverse relationship with BI-L and SWEM-L. While farm diversification is generally agreed upon to be a risk-reducing practice, for Bhutanese farmers it may divert limited resources away from a few known and relatively reliable staple crops needed for subsistence and thus be perceived as actually increasing risk exposure.

Examining income diversification as measured through the BI-I and SWEM-I metrics, it is apparent that younger farmers are more likely to have diverse income streams. Additionally, female farmers have less diversified income sources than their male counterparts. Households with larger farms tend to have more diversity in their income streams. Notably, total income is shown to not be a reliable predictor of farm diversification. Low-income farmers are just as likely to diversify their income streams as those in higher income brackets. Both independent variables gain safe decisions and loss safe decisions show significance when predicting BI-I and SWEM-I, but the direction of the effects is opposing. The effect of the gain safe decisions is positive (as predicted) while that of loss safe decisions is negative. The cause of this is ambiguous, although diversifying income might be seen as risk-reducing for gains (decreasing income variance), while simultaneously increasing the potential for losses to occur if new, unproven sources are obtained. This question warrants further study in the context of developing, rural markets.

The debt to income ratio DIR is most influenced by the use of a power-tiller. This most likely indicates that one of the Bhutanese farmers' primary sources of debt is incurred to either purchase or rent one. The only other variable with predictive power for DIR is loss safe decisions, which also has a positive effect. This effect is in the opposite direction of what was hypothesised. In light of the prior result, it is plausible that the more risk-averse for losses farmers are, the more debt they are willing to incur to reduce the risk of harvest loss through employing modern tilling methods.

The adoption of modern rice varieties MRAP is shown to increase with age, education, available labour, and extension agent visits. The use of a power-tiller has a large, negative effect on adoption. The reason for this is not clear, and further investigation is needed. Finally, both gain and loss safe decisions failed to predict the adoption of modern seed varieties, indicating that the household-level factors mentioned above more heavily influence adoption than do individual risk preferences.

The standardised index for nitrogenous fertiliser application SNAI is only significantly predicted by farm size and extension agent visits, both of which have a relatively small, negative effect. Pesticide use, as measured through SPAI, is shown to have an inverse relationship with both farm size and loss safe decisions. Smaller farms appear to be more reliant on fertilisers and pesticides than larger ones. Additionally, extension agents may be successful in promoting other methods of improving soil quality, but they have fallen short in their efforts to meet the RGOB's organic by 2020 vision through decreasing pesticide use. Finally, participation in on-farm trials has a positive relationship with both power-tiller use and additional farm labour. Participation is not dependent on risk preference for either gains or losses.

\section{Discussion}

The Tobit regression model results demonstrate a preliminary ability to predict an array of risk-dependent agricultural field behaviours within Bhutan. On the basis of these initial findings, future research and refinement are needed. Income and labour deficit appear to be the least useful predictors while farm size, labour, and loss safe decisions are among the most significant. This study was predicated on a priori field behaviours being a function of risk preference for both gains and losses. However, gain safe decisions failed to predict most farm diversification metrics, DIR, and all farm management metrics. Additionally, loss safe decisions showed no significance when predicting PPR and most farm management metrics. Despite the use of a sophisticated elicitation method and statistical rigour, the safe decision metrics are unable to predict many of the field behaviours tested. Two potential reasons for these shortcomings were 
identified.

The first possible explanation of the results is the failure to account for ambiguity aversion. Since the exact probabilities of the potential outcomes of farming decisions are not known, it is plausible that a measure of ambiguity aversion may be better suited to predict agricultural field behaviours than risk aversion. Barham, Chavas [55] demonstrated that the significance of ambiguity aversion is greater than that of risk aversion in predicting the adoption of genetically modified corn in the United States. In the context of a developing country, Engle Warnick, Escobal [56] found that ambiguity aversion reduces the likelihood that farmers will cultivate multiple varieties of their primary crop. In both developed and developing countries, the reliability of ambiguity aversion over risk aversion to predict agricultural field behaviours remains a subject largely open to inquiry. Additionally, a standardised procedure of measuring ambiguity aversion across cultures and literacy levels would be a valuable addition to the literature. The availability of such an instrument would enable results across studies to be compared with relative ease.

The second explanation of the findings of this study is the possible presence of 'background risk' [57]. Without taking participants into a lab, where their decisions are as far removed from the real world as possible, the results of the risk preference elicitation may be skewed by prior behaviour. Under the assumptions of background risk, an individual's experimentally elicited risk preference may be interpreted only as a fragment of their actual risk preference which is observable through an aggregation of their decisions. If, for example, a participant engages in risk-reducing behaviours, she might be more prone to risk seeking on the LCT since there is little risk in other aspects of her life. The effect of background risk may be exacerbated by priming participants to think about their previous risk-dependent behaviours (such as agricultural decisions) prior to engaging in the LCT. Because of the geography of Bhutan, it was not feasible to take farmers into a lab for an isolated risk preference elicitation and then visit their homes to gather data on their farming practices. As such, the presence of background risk may have been a factor influencing the results of this study.

\section{Conclusions}

This article took the first step in understanding the drivers of risk-dependent agricultural field behaviours within Bhutan. In the context of a country with a reliance on agriculture, the need to quantify the determinants of these behaviours cannot be understated. Increased efficiency and efficacy of government policies, non-profit work, and extension officer efforts are some of the potential benefits such an understanding would yield. Using cross-sectional data gathered from the Punakha-Wangdue valley during the spring of 2018, a multivariate Tobit regression analysis was employed to predict ten field behaviours. Using demographic, socio-economic, and risk preference independent variables, this study was able to identify what most influences these behaviours.

On the basis of this article's findings, it is shown that measures to promote income diversification or curb fertiliser and pesticide application can be developed and targeted to households based on their farm size. Additionally, income diversification programmes can be customised based on the HoH's age and gender. Policy to increase farm diversification may consider the HoH's level of education as well as the available farm labour. Finally, it is shown that households who are risk averse for losses tend to diversify both their farm and their income streams to lesser degrees. In the loss domain, Bhutanese farmers seem to be influenced by potential reductions in yield and income.

There is a need for further research in Bhutan and around the world that aims to develop progressively more robust models of farmers' decision making. This is becoming increasingly important in the face of changing economic and environmental conditions. Understanding the role that risk preference and other factors play in determining agricultural field behaviours will help stakeholders better allocate their resources and target interventions. This is hoped to result in improved health, environmental, and economic outcomes for at-risk agrarian populations. This article took the first step at gaining such an understanding in Bhutan and added to the ever-expanding body of literature globally that aims at incorporating the findings of behavioural economics into the world of agriculture.

\section{Acknowledgements}

Many thanks to Natshok Wangdi of the Royal Government of Bhutan's Ministry of Agriculture and Forests for assistance in translation during the interview process. The authors are also grateful to the extension agents and dzongkhag administrative staff of Punakha and Wangdue Phodrang for their continued support and consent during the data collection process.

\section{References}

[1] Chavas, J. P., R. G. Chambers, and R. D. Pope, Production Economics and Farm Management: a Century of Contributions. American Journal of Agricultural Economics, 2010. 92 (2): p. 356-375.

[2] Lin, W., G. W. Dean, and C. V. Moore, An Empirical Test of Utility vs. Profit Maximization in Agricultural Production. American Journal of Agricultural Economics, 1974. 56 (3): p. 497-508.

[3] Lusk, J. L. and K. H. Coble, Risk Perceptions, Risk Preference, and Acceptance of Risky Food. American Journal of Agricultural Economics, 2005. 87 (2): p. 393-405.

[4] Anderson, L. R. and J. M. Mellor, Predicting health behaviors with an experimental measure of risk preference. J Health Econ, 2008. 27 (5): p. 1260-74.

[5] Dohmen, T., et al., Are Risk Aversion and Impatience Related to Cognitive Ability? American Economic Review, 2010. 100 (3): p. 1238-1260. 
[6] National Statistics Bureau, 2017 Population and Housing Census of Bhutan: National Report, N. S. B. o. Bhutan, Editor. 2018, Loday Natshog Communications: Thimphu, Bhutan.

[7] National Statistics Bureau, Statistical Yearbook of Bhutan 2018, N. S. Bureau, Editor. 2018: Thimphu, Bhutan.

[8] Just, R. E., An Investigation of the Importance of Risk in Farmers' Decisions. American Journal of Agricultural Economics, 1974. 56 (1): p. 14-25.

[9] Liu, E. M. and J. Huang, Risk preferences and pesticide use by cotton farmers in China. Journal of Development Economics, 2013. 103: p. 202-215.

[10] Le Cotty, T., et al., Linking Risk Aversion, Time Preference and Fertiliser Use in Burkina Faso. The Journal of Development Studies, 2017. 54 (11): p. 1991-2006.

[11] Khor, L. Y., et al., Impact of risk aversion on fertiliser use: evidence from Vietnam. Oxford Development Studies, 2018. 46 (4): p. 483-496.

[12] Gong, Y., et al., Farmers' risk preferences and pesticide use decisions: evidence from field experiments in China. Agricultural Economics, 2016. 47 (4): p. 411-421.

[13] Asravor, R. K., Farmers' risk preference and the adoption of risk management strategies in Northern Ghana. Journal of Environmental Planning and Management, 2018: p. 1-20.

[14] Hellerstein, D., N. Higgins, and J. Horowitz, The predictive power of risk preference measures for farming decisions. European Review of Agricultural Economics, 2013. 40 (5): p. 807-833.

[15] Vollmer, E., D. Hermann, and O. Mußhoff, Is the risk attitude measured with the Holt and Laury task reflected in farmers' production risk? European Review of Agricultural Economics, 2017. 44 (3): p. 399-424.

[16] Department of Agriculture, National Framework for Organic Farming in Bhutan, D. o. A. M. o. Agriculture, Editor. 2006. p. $1-43$.

[17] Tashi, S. and K. Wangchuk, Prospects of Organic Farming in Bhutan: A SWOT Analysis. Advances in Agriculture, 2016. 2016: p. 1-9.

[18] World Bank, South Asia: Extremes of Water Scarcity and Excess, in Turn down the heat: climate extremes, regional impacts, and the case for resilience. 2013, International Bank for Reconstruction and Development, World Bank: Washington, DC. p. 105-146.

[19] Dem, P. and N. Minot, Agricultural trade in Bhutan: Patterns, trends; and economic impact. 2010, International Food Policy Research Institute (IFPRI) and Ministry of Agriculture and Forests (MoAF): Washington, D. C.

[20] Tanaka, T., C. F. Camerer, and Q. Nguyen, Risk and Time Preferences: Linking Experimental and Household Survey Data from Vietnam. American Economic Review, 2010. 100 (1): p. 557-571.

[21] Liu, E. M., Time to Change What to Sow: Risk Preferences and Technology Adoption Decisions of Cotton Farmers in China. Review of Economics and Statistics, 2013. 95 (4): p. 1386-1403.

[22] Holt, C. A. and S. K. Laury, Risk Aversion and Incentive Effects. American Economic Review, 2002. 92 (5): p.
$1644-1655$

[23] Tversky, A. and D. Kahneman, Loss Aversion in Riskless Choice: A Reference-Dependent Model. The Quarterly Journal of Economics, 1991. 106 (4): p. 1039-1061.

[24] Von-Neumann, J. and O. Morgenstern, Theory of games and economic behavior. 1944: Princeton University Press Princeton, NJ.

[25] Hirschauer, N., et al., Eliciting risk attitudes - how to avoid mean and variance bias in Holt-and-Laury lotteries. Applied Economics Letters, 2013. 21 (1): p. 35-38.

[26] Lin, B. B., Resilience in Agriculture through Crop Diversification: Adaptive Management for Environmental Change. BioScience, 2011. 61 (3): p. 183-193.

[27] Baumgärtner, S. and M. F. Quaas, Managing increasing environmental risks through agrobiodiversity and agrienvironmental policies. Agricultural Economics, 2010. 41 (5): p. 483-496.

[28] Joshi, P. K., et al., Agriculture diversification in South Asia: patterns, determinants and policy implications. Economic and Political Weekly, 2004. 39 (24): p. 2457-2467.

[29] Dasgupta, P., Uncertainty, Insurance, and Social Norms, in An inquiry into well-being and destitution. 1993, Oxford University Press: Oxford. p. 189-217.

[30] Zhu, Y., et al., Genetic diversity and disease control in rice. Nature, 2000. 406 (6797): p. 718-22.

[31] Keesing, F., et al., Impacts of biodiversity on the emergence and transmission of infectious diseases. Nature, 2010. 468 (7324): p. $647-52$.

[32] Birthal, P. S., et al., Agricultural diversification in North eastern region of India: Implications for growth and equity. Indian Journal of Agricultural Economics, 2006. 61 (3): p. 328-340.

[33] Michler, J. D. and A. L. Josephson, To Specialize or Diversify: Agricultural Diversity and Poverty Dynamics in Ethiopia. World Development, 2016. 89: p. 214-226.

[34] Di Falco, S., et al., Agrobiodiversity, farm profits and land fragmentation: Evidence from Bulgaria. Land Use Policy, 2010. 27 (3): p. 763-771.

[35] Waha, K., et al., Agricultural diversification as an important strategy for achieving food security in Africa. Global Change Biology, 2018. 24 (8): p. 3390-3400.

[36] Di Falco, S., J.-P. Chavas, and M. Smale, Farmer management of production risk on degraded lands: the role of wheat variety diversity in the Tigray region, Ethiopia. Agricultural Economics, 2007. 36 (2): p. 147-156.

[37] McNamara, K. T. and C. Weiss, Farm Household Income and On- and Off-Farm Diversification. Journal of Agricultural and Applied Economics, 2005. 37 (01): p. 37-48.

[38] Berry, C. H., Corporate Growth and Diversification. The Journal of Law and Economics, 1971. 14 (2): p. 371-383.

[39] Pope, R. D. and R. Prescott, Diversification in Relation to Farm Size and Other Socioeconomic Characteristics. American Journal of Agricultural Economics, 1980. 62 (3): p. 554-559. 
[40] Shannon, C. E., A mathematical theory of communication. Bell System Technical Journal, 1948. 27: p. 379-423 and 623-656.

[41] Wiener, N., Cybernetics: Control and communication in the animal and the machine. 1948, Cambridge, MA: MIT Press.

[42] Campbell, K. and A. Mínguez-Vera, Gender Diversity in the Boardroom and Firm Financial Performance. Journal of Business Ethics, 2007. 83 (3): p. 435-451.

[43] Levy, H. and M. Sarnat, International diversification of investment portfolios. The American Economic Review, 1970. 60 (4): p. 668-675.

[44] Rossi, S. P. S., M. S. Schwaiger, and G. Winkler, How loan portfolio diversification affects risk, efficiency and capitalization: A managerial behavior model for Austrian banks. Journal of Banking \& Finance, 2009. 33 (12): p. 2218-2226.

[45] Weltin, M., et al., Analysing behavioural differences of farm households: An example of income diversification strategies based on European farm survey data. Land Use Policy, 2017. 62: p. 172-184.

[46] González, M., et al., Family firms and debt: Risk aversion versus risk of losing control. Journal of Business Research, 2013. 66 (11): p. 2308-2320.

[47] Eckel, C. C., et al., Debt Aversion and the Demand for Loans for Postsecondary Education. Public Finance Review, 2016. 35 (2): p. 233-262.

[48] Shrestha, S., An economic impact assessment of the rice research program in Bhutan. 2004, Los Baños, Philippines: International Rice Research Institute. 51.
[49] Feder, G., Farm size, risk aversion and the adoption of new technology under uncertainty. Oxford Economic Papers, 1980. 32 (2): p. 263-283.

[50] Knight, J., S. Weir, and T. Woldehanna, The role of education in facilitating risk-taking and innovation in agriculture. Journal of Development Studies, 2003. 39 (6): p. 1-22.

[51] Roosen, J. and D. A. Hennessy, Tests for the Role of Risk Aversion on Input Use. American Journal of Agricultural Economics, 2003. 85 (1): p. 30-43.

[52] Tshewang, S., et al., Weed management challenges in rice (Oryza sativa L.) for food security in Bhutan: A review. Crop Protection, 2016. 90: p. 117-124.

[53] Ghadim, A. K. A., D. J. Pannell, and M. P. Burton, Risk, uncertainty, and learning in adoption of a crop innovation. Agricultural Economics, 2005. 33 (1): p. 1-9.

[54] Tobin, J., Estimation of relationships for limited dependent variables. Econometrica: journal of the Econometric Society, 1958. 26: p. 24-36.

[55] Barham, B. L., et al., The roles of risk and ambiguity in technology adoption. Journal of Economic Behavior \& Organization, 2014. 97: p. 204-218.

[56] Engle Warnick, J. C., J. Escobal, and S. C. Laszlo, Ambiguity Aversion and Portfolio Choice in Small-Scale Peruvian Farming. The B. E. Journal of Economic Analysis \& Policy, 2011. 11 (1).

[57] Harrison, G. W., J. A. List, and C. Towe, Naturally occurring preferences and exogenous laboratory experiments: A case study of risk aversion. Econometrica, 2007. 75 (2): p. 433-458. 